\title{
What's new in intensive care: tracheostomy - what is known and what remains to be determined
}

\author{
José Aquino Esperanza ${ }^{1,2,3}$, Paolo Pelosii ${ }^{4,5}$ and Lluís Blanch ${ }^{1,6,7^{*}}$ (I)
}

๑ 2019 Springer-Verlag GmbH Germany, part of Springer Nature

Tracheostomy is done in $10-15 \%$ of patients undergoing mechanical ventilation (MV), and the prevalence has increased over the past 20 years [1]. The main indications are prolonged MV and difficult or prolonged weaning, and most patients requiring tracheostomy are admitted to the intensive care unit (ICU) for acute respiratory failure, coma, neuromuscular disease, or trauma. Percutaneous dilatational tracheostomy (PDT) can be performed in the ICU by non-surgeons, and clinical guidelines recommend this approach unless contraindicated [2].

\section{Does tracheostomy affect lung mechanics?}

Theoretically, tracheostomy could reduce inspiratory and expiratory resistive loads, because compared to endotracheal tubes (ETT), cannulae have larger inner diameters and are less susceptible to thermolabile deformation and obstruction due to secretions. Tracheostomy could also improve expiratory flow, thus minimizing intrinsic positive-end expiratory pressure (PEEPi). Both these factors should reduce the work of breathing. Moreover, it is tempting to assume that these improvements could reduce patient-ventilator dyssynchrony. However, shortterm physiological studies showed conflicted evidence regarding mechanics and without explicit analysis of dyssynchrony. While some revealed a reduction in work of breathing (WOB), airway occlusion pressure and PEEPi $[3,4]$, with one of them reporting the disappearance of ineffective efforts (IE) after tracheostomy in three subjects [3]; others did not [5], despite the fact that these

\footnotetext{
*Correspondence: Iblanch@tauli.cat

${ }^{1}$ Critical Care Center, Institut d'Investigació i Innovació Parc Taulí I3PT, Hospital Universitarí Parc Taulí, Sabadell, Spain

Full author information is available at the end of the article
}

observed results are difficult to generalize mainly because differences in inspiratory flow, all of them were patients with COPD and bronchiectasis, heterogeneity in the ventilator modes, and positive results only when WOB was expressed in Jules/L.

\section{Is there an optimal time to perform tracheostomy?} General population of critically ill patients

Clinical data about timing are inconclusive. Moreover, clinicians' ability to predict prolonged intubation during the first days of MV is poor [1]. Recent trials comparing "early" (6-8 and <4 days) versus "late" (13-15 and $>10$ days) tracheostomy $[6,7]$ found no difference in overall mortality, hospital length of stay (LOS), or ICULOS. Current meta-analyses $[8,9]$ showed that timing was not associated with all-cause ICU mortality or 1-year mortality. Moreover, one of them indicates that early tracheostomy decreased the incidence of ventilator-associated pneumonia [8], and the other resulted in decreased use of sedation [9]. Importantly, randomization to early tracheostomy was associated with more procedures without any real benefit in outcome and could result in immediate, short- and long-term complications. Furthermore, given that most patients randomized to late tracheostomy were not tracheostomized, and eventually extubated with similarly low rates of complications and even weaned between 14, 28 days or a month after MV initiation, future studies should focus on prolonged endotracheal intubation as a route to avoid tracheostomy. Therefore, the question of the optimal time for tracheostomy remains unanswered, compelling to weigh the risk against expected, but unproven benefit. Thus, it might be prudent to wait at least 10-14 days after initiating MV.

\section{Springer}


Table 1 Current evidence from Randomized Controlled Trials and Meta-analysis regarding tracheostomy timing in different groups of critically ill patients

\begin{tabular}{|c|c|}
\hline Population and study & Timing and outcomes \\
\hline Mixed ICU-RCT [6] & $\begin{array}{l}\text { Early ( } 6-8 \text { days) versus late (13-15 days): no difference in VAP, Hospital-LOS, Survival at } 28 \text { days and } 1 \text { year. More proce- } \\
\text { dures made in early group }\end{array}$ \\
\hline Mixed ICU-RCT [7] & $\begin{array}{l}\text { Early ( } 4 \text { days) versus Late ( } 10 \text { days or more): no difference in } 30 \text { days-mortality and } 2 \text { years survival. More procedures } \\
\text { were made in the early group }\end{array}$ \\
\hline Mixed ICU—meta-analysis [8] & Early versus Late: no difference in mortality, might be associated with lower incidence of VAP \\
\hline Mixed ICU—meta-analysis [9] & $\begin{array}{l}\text { Early ( }<10 \text { days) versus Late ( }>10 \text { days): no difference in mortality, ICU-LOS and VAP. Less sedation and more procedures } \\
\text { made in early group }\end{array}$ \\
\hline Stroke patients-RCT [12] & Early (1-3 days) versus Late (7-14 days): lower ICU-mortality and 60 days-mortality in Early group \\
\hline $\begin{array}{l}\text { Acute brain injury patients- } \\
\text { meta-analysis [10] }\end{array}$ & $\begin{array}{l}\text { Early ( }<10 \text { days) versus (Late }>10 \text { days): early may reduce ICU and Long-term mortality and reduce ICU-LOS. More } \\
\text { procedures were made in the early group }\end{array}$ \\
\hline
\end{tabular}

ICU intensive care unit, LOS length of stay, RCT randomized controlled trial, VAP ventilator associated pneumonia

\section{Neurocritical patients}

A meta-analysis of acute brain injury patients requiring early tracheostomy resulted in shorter ICU-LOS and lower ICU and long-term mortality, although these results might merely indicate a shift in the location of patients and death to long-term facilities [10]. In addition, in patients with spinal cord injury, early tracheostomy decreased mortality, hospital-LOS and pulmonary complications; moreover, PDT techniques showed to be equally safe and faster than surgical in patients with anterior cervical spine fusion and could be safely performed even after 15 days with low rates of complications [11]. Similarly, in patients with stroke, early tracheostomy is associated with discontinuation of MV, earlier decannulation, less sedation, and improved survival [12].

\section{Is there an optimal technique?}

PDT is more common than surgical tracheostomy in European ICUs, meanwhile elsewhere they are equally distributed. Among general populations of critically ill adult patients, PDT showed to be faster, results in less major bleeding, and with lower rates of stoma infection; moreover, single step dilator (SSD) and multiple step dilator (MDT) were associated with the lowest intraprocedural risk and should be the preferred PDT technique [13]. Different maneuvers aiming to minimize complications and improve results include: ultrasound-guided PDT, bronchoscopy-guided PDT, and bronchoscopyguided with double-lumen ETTs.

However, bronchoscopy guidance, combined or not with ultrasound, is routinely and widely performed in the ICU and should be always considered to better determine the exact needle insertion, tracheostomy positioning and increase safety during the procedure. Additionally, in acutely brain injured patients, SSD has showed to be safe with only transient changes in intracranial pressure (ICP), cerebral hypertension and without compromising cerebral oxygenation [14]; furthermore, tracheostomy performed whenever ICP is not critically unstable, proved to be useful and safe.

\section{Outcome after tracheostomy}

MV patients who require tracheostomy have a higher mortality rate at 1 year and afterward. Furthermore, patients older than 45 years under MV longer than 14 days are prone to developing disabilities and functional dependencies after ICU and hospital discharge. Tracheostomized critically ill patients also complain of pain, difficulties in communicating, anxiety, and depression [15]. For these reasons, we strongly recommend out-of-hospital follow-up for tracheostomized patients for at least 1 year after the procedure. Importantly, future studies should incorporate patient-centered outcomes including, comfort, mobility, functional outcomes and discharge destination (Table 1).

\section{Where should we go from here?}

Unanswered questions still remain, such as: (1) Is there a "best" PDT technique for critically ill patients? (2) Is there an optimal time that reduces unnecessary procedures and also benefits critically ill patients? (3) Should different PDT procedures be used for patients with different characteristics (e.g., obese, neurocritical, high risk of bleeding)? (4) Does tracheostomy improve patientventilator interactions substantially? and (5) How can we improve long-term outcomes and quality of life in tracheostomized patients?

Until we have evidence-based information, decisions about tracheostomy should always be tailored to individual patients. We believe that future improvements are likely to come from better timing for specific categories of patients and better decision-making algorithms, rather than from new technological developments. To summarize, in critically ill patients, tracheostomy should be 
performed when clear clinical indications are present, after careful multidisciplinary evaluation taking into account the patient's life expectancy, quality of life, and future interactions with their families and caregivers after ICU and hospital discharge.

\section{Author details}

${ }^{1}$ Critical Care Center, Institut d'Investigació i Innovació Parc Taulí I3PT, Hospital Universitarí Parc Taulí, Sabadell, Spain. ${ }^{2}$ Universitat de Barcelona, Facultat de Medicina, Barcelona, Spain. ${ }^{3}$ Department of Internal Medicine, Critical Care Unit, Centro de Educación Médica e Investigaciones Clínicas CEMIC, Buenos Aires, Argentina. ${ }^{4}$ Department of Surgical Sciences and Integrated Diagnostics, University of Genoa, Genoa, Italy. ${ }^{5}$ Anesthesia and Intensive Care, IRCCS for Oncology and Neurosciences, San Martino Policlinico Hospital, Genoa, Italy. ${ }^{6}$ Centro de Investigación Biomédica en Red Enfermedades Respiratorias (CIBERES), Instituto de Salúd Carlos III, Madrid, Spain. ${ }^{7}$ Universitat Autonoma de Barcelona, Parc Taulí 1, 08208 Sabadell, Spain.

\section{Compliance with ethical standards}

\section{Conflicts of interest}

The authors declare that they have no conflict of interest.

\section{Publisher's Note}

Springer Nature remains neutral with regard to jurisdictional claims in published maps and institutional affiliations.

Received: 3 July 2019 Accepted: 19 August 2019

Published online: 26 August 2019

\section{References}

1. Frutos-Vivar F, Esteban A, Apezteguía C et al (2005) Outcome of mechanically ventilated patients who require a tracheostomy. Crit Care Med 33:290-298

2. Trouillet IL, Collange O, Belafia F et al (2018) Tracheotomy in the intensive care unit: Guidelines from a French expert panel: The French Intensive Care Society and the French Society of Anaesthesia and Intensive Care Medicine. Anaesth Crit Care Pain Med 37:281-294
3. Diehl J, El Atrous D, Touchard D et al (1999) Changes in the work of breathing induced by tracheotomy in ventilator- dependent patients. Am J Respir Crit Care Med 159:383-388

4. Davis K, Campbell RS, Johannigman JA et al (1999) Changes in respiratory mechanics after tracheostomy. Arch Surg 134:59-62

5. Lin MC, Huang CC, Yang CT et al (1999) Pulmonary mechanics in patients with prolonged mechanical ventilation requiring tracheostomy. Anaesth Intensive Care 27:581-585

6. Terragni PP, Antonelli M, Fumagalli R et al (2010) Early vs late tracheotomy for prevention of pneumonia in mechanically ventilated adult ICU patients: a randomized controlled trial. JAMA 303:1483-1489

7. Young D, Harrison DA, Cuthbertson BH, Rowan K (2013) Effect of early vs late tracheostomy placement on survival in patients receiving mechanical ventilation: the TracMan randomized trial. JAMA 309:2121-2129

8. Siempos II, Ntaidou TK, Filippidis FT, Choi AMK (2015) Effect of early versus late or no tracheostomy on mortality and pneumonia of critically ill patients receiving mechanical ventilation: A systematic review and metaanalysis. Lancet Respir Med 3:150-158

9. Szakmany T, Russell P, Wilkes AR, Hall JE (2015) Effect of early tracheostomy on resource utilization and clinical outcomes in critically ill patients: meta-analysis of randomized controlled trials. Br J Anaesth 114:396-405

10. Mccredie VA, Alali AS, Scales DC et al (2016) Effect of early versus late tracheostomy or prolonged intubation in critically ill patients with acute brain injury: a systematic review and meta-analysis. Neurocrit Care 26:14-25

11. Leelapattana P, Fleming JC, Gurr KR et al (2012) Predicting the need for tracheostomy in patients with cervical spinal cord injury. J Traum Acute Care Surg 73:880-884

12. Bösel J, Schiller P, Hook Y et al (2013) Stroke-related early tracheostomy versus prolonged orotracheal intubation in neurocritical care trial (SETPOINT): a randomized pilot trial. Stroke 44:21-28

13. Putensen C, Theuerkauf N, Guenther U et al (2014) Percutaneous and surgical tracheostomy in critically ill adult patients: a meta-analysis. Crit Care 18:1-21

14. Kuechler JN, Abusamha A, Ziemann S et al (2015) Impact of percutaneous dilatational tracheostomy in brain injured patients. Clin Neurol Neurosurg 137:137-141

15. Herridge MS, Chu LM, Matte A et al (2016) The RECOVER program: disability risk groups and 1-year outcome after 7 or more days of mechanical ventilation. Am J Respir Crit Care Med 194:831-844 